\title{
Twenty-five gauge vitrectomy in uveitis
}

\author{
Vitrectomia 25-gauge em uveítes
}

Roger Roberto Wada Kamel ${ }^{1}$, Tiago Eugênio Faria e Arantes ${ }^{1}$, Claudio Renato Garcia ${ }^{1}$, Cristina Muccioli ${ }^{2}$

\begin{abstract}
Purpose: To evaluate anatomical and functional results of 25-gauge transconjunctival sutureless pars plana vitrectomy in patients with uveitis.

Methods: Vitrectomy was performed on 20 eyes with residual vitritis secondary to infectious and noninfectious uveitis. Patients were evaluated 1 week before surgery and after surgery at day 1, week 1, week 4 and week 12. Visual acuity (VA), intraocular pressure, anterior chamber cells and flare and vitreous haze were measured.

Results: Mean VA improved from $2.06 \pm 0.94 \operatorname{logMAR}$ before surgery to $0.58 \pm$ 0.46 logMAR at week $12(p<0.05)$. No case required conversion to standard 20-gauge instrumentation or suture placement, no intraoperative complications were noted. Transient postoperative hypotony was seen in three eyes. One patient with toxoplasmic retinochoroiditis had a relapse during follow-up.

Conclusion: 25-gauge vitrectomy has proven its efficacy on cleansing vitreous opacities and improving visual acuity on patients with residual vitritis secondary to uveitis with minimal postoperative inflammation and complications.
\end{abstract}

Keywords: Vitrectomy; Uveitis; Vitreous body; Eye infections

\section{RESUMO}

Objetivo: Avaliar os resultados anatômicos e funcionais da vitrectomia via pars plana 25-gauge transconjuntival sem sutura em pacientes com uveítes.

Métodos: Realizou-se vitrectomia em 20 olhos com vitreíte residual secundária a uveíte infecciosa e não infecciosa. Os pacientes foram avaliados uma semana antes e após a cirurgia, no primeiro dia, 11a , $4^{a}$ e $12^{a}$ semana. Acuidade visual (AV), pressão intraocular, células e "flare" na câmara anterior e "haze" vitreo foram medidos.

Resultados: A AV média melhorou de 2,06 \pm 0,94 logMAR antes da cirurgia para 0,58 \pm $0,46 \log M A R$ na $12^{a}$ semana $(p<0,05)$. Nenhum caso necessitou de conversão para instrumentos de 20-gauge ou realização de sutura e não foram observadas complicações intraoperatórias. Hipotonia transitória foi observada em três olhos. Um paciente com retinocoroidite por toxoplasmose teve recidiva durante o acompanhamento.

Conclusão: Vitrectomia 25-gauge provou sua eficácia na remoção do vítreo opacificado e na melhora da AV em pacientes com vitreíte residual secundária a uveítes, com mínima inflamação pós-operatória e complicações.

Descritores: Vitrectomia; Uveítes; Corpo vitreo; Infecçōes oculares

\section{INTRODUCTION}

Vitreoretinal complications including vitreous opacities, vitreoretinal traction, or epiretinal membranes are common ocular findings during the follow-up of patients with inflammation of the posterior segment. Pars plana vitrectomy, traditionally performed with 20-gauge instrumentation in association with pharmacotherapy has been a valuable tool, promoting cleansing of the vitreous opacities and repair of structural complications ${ }^{(1-3)}$. Despite these facts, intraocular surgery can also exacerbate the inflammation in eyes with uveitis by activating the underlying inflammatory process and the procedure itself can cause an unusually severe inflammatory response, abnormal bleeding or unexpected postoperative intraocular pressure (IOP) responses ${ }^{(4)}$.

In 2002, Fujii et al. demonstrated the feasibility and safety of a transconjunctival sutureless 25 -gauge vitrectomy system ${ }^{(5,6)}$ and, since then, this system has been used in numerous vitreoretinal diseases. Among the advantages of this sutureless transconjunctival technique we can consider the minimization of the surgically induced trauma caused by the eye manipulation and sutures (along with the possible reactions related to the suture material itself) and the shortening of the time for the procedure by avoiding the opening and suture of sclera and conjunctiva separately, leading to a reduction in postoperative inflammation and quicker recovery ${ }^{(7-10)}$.

This technique can be considered as ideally designed for eyes with uveitis, because the least traumatic surgical technique with minimization of postoperative inflammatory response is the key for the healing process in this group of patients.

The purpose of this study was to evaluate the clinical and functional results of 25-gauge pars plana vitrectomy ( $25 \mathrm{~g}$ PPV) in the management of patients with vitreous opacities secondary to inflammation of the posterior segment of the eye.

\section{METHODS}

Twenty consecutive eyes of 19 consecutive patients with dense residual vitreous opacities secondary to posterior segment inflammation underwent surgical procedure between April/2007 to July/2008. All the patients were recruited from the Uveitis and AIDS service of the Universidade Federal de São Paulo - UNIFESP, Brazil. Informed consent was obtained from all patients and the study was approved by the Institution Ethics Committee.

Surgeries were performed after the inflammation was controlled by medical treatment and all patients had quiescent uveitis for at least 3 months. Eyes with previous vitreoretinal surgery or retinal detachment were not included in this study. Diagnostic evaluation included a full medical history, clinical evaluation, and appropriate laboratory investigation.

Patients had a follow-up evaluation one week before surgery (baseline) and after surgery at day 1, week 1, week 4 and week 12. Ophthalmic evaluation included visual acuity (VA) measured by 
Early Treatment Diabetic Retinopathy Study (ETDRS) chart, anterior and posterior segment slit-lamp evaluation, dilated fundus examination using binocular indirect ophthalmoscope and Goldmann applanation tonometry. Ocular ultrasound and Optical Coherence Tomography were performed when indicated. Cell and flare count in the anterior chamber were determined according to the SUN working group grading scheme ${ }^{(11)}$, vitreous haze was graded based on standard photographs developed by Nussenblatt et al. ${ }^{(12)}$ Hypotony was defined as intraocular pressure (IOP) of $<8 \mathrm{mmHg}$. Conversion of counting fingers at two feet and hand-motion at two feet VA to Snellen equivalent was made according to the method proposed by Holladay ${ }^{(13)}$ and were given values of $0.01(+2.0 \log M A R)$ and 0.001 (+3.0 logMAR), respectively.

Patients with non-infectious etiology already on systemic steroids (two patients) had their prescription changed (40 mg/day on surgery and tapered over the follow-up period), other three patients that were not under immunosuppressive treatment received an intraoperative subtenon triamcinolone acetonide injection $(1 \mathrm{ml}$ of a $40 \mathrm{mg} / \mathrm{ml}$ solution).

\section{Surgical technique}

The periocular skin was prepared thoroughly with $5 \%$ povidone-iodine, which was followed by instillation of drops of 0,5\% povidone-iodine into the inferior conjunctival fornix. All patients received peribulbar anesthesia (50:50 0,5\% bupivacaine and 2\% lidocaine). The $25 \mathrm{~g}$ PPV was performed using the Alcon Accurus vitrectomy system (Alcon Labs, Fort Worth, TX, USA) with the insertion of a cannula using a beveled trocar after displacement of the conjunctiva to misalign the conjunctival and scleral incisions. Transscleral cannulas were placed through the pars plana, 3.5 to $4.0 \mathrm{~mm}$ from the limbus, in the superonasal, superotemporal, and inferotemporal quadrants. The inferotemporal cannula was the site of infusion, and both superior quadrant cannulas were used for intraocular instrumentation. All eyes underwent total vitrectomy followed by elevation and removal of the posterior hyaloid membrane and fluid/gas exchange. Other procedures like epiretinal membrane peeling and endolaser photocoagulation were performed as needed during vitreous surgery. The peripheral retina was inspected using the wide-field contact lens (same used for the surgical procedure) and scleral depression with the trocars still in place. At the end of surgery, the infusion line was clamped, and the superonasal and superotemporal canullas were removed. The sclerotomy site was inspected for fluid or air leakage, and then the infusion cannula was removed. Total time for the procedure (from insertion of the trocars to removal of the cannulas) was recorded. For eyes with lens opacification, cataract phacoemulsification was combined with vitrectomy.

Postoperatively, topical $0.3 \%$ ciprofloxacin or $0.5 \%$ moxifloxacin were administered four times daily for 10 days and $1 \%$ topical prednisolone acetate, 6 times a day with slow tapering over the follow-up period according to the postoperative recovery. Patients in use of systemic anti-inflammatory agents maintained the therapy during the follow-up.

\section{Statistical analysis}

Statistical analysis was performed using SigmaStat 3.11 (SPSS Inc, Chicago, IL). The distribution of continuous variable is expressed as mean \pm standard deviation and categorical data are presented as frequencies. Changes in VA and IOP over time were analyzed by Friedman's repeated measures analysis of variance on ranks, with statistical significance set at two-sided $p<0.05$.

\section{RESULTS}

The mean age of the 12 women and 7 men was $41.79 \pm 14.63$ years (range 16 to 65 years). The etiology was diagnosed as infectious in 13 eyes (65\%), non infectious in 4 eyes (20\%) and idiopathic in 3 eyes (15\%) (Table 1). One patient with posterior uveitis secondary to tuberculosis had bilateral disease and underwent surgery in both eyes. Eighteen eyes were phakic and two aphakic before surgery. Mean operative time was $31.15 \pm 14.55$ minutes (Median 27.50 minutes). Combined cataract phacoemulsification with IOL implantation was performed in three patients. Two patients who developed cataract during the follow-up also underwent phacoemulsification with IOL implantation before the final visit. No case required conversion to standard 20-gauge instrumentation or suture placement in the sclerotomies and no major intra or postoperative complications were noted.

Improvement in visual acuity was achieved in all patients of our series, mean VA improved from $2.06 \pm 0.94$ logMAR before surgery to $1.91 \pm 0.93,1.16 \pm 0.94,0.71 \pm 0.56$ and $0.58 \pm 0.46 \log M A R$, respectively at day 1 , week 1 , week 4 and week 12 (Figure 1).

Anterior chamber cell activity of $1+$ or greater was observed in 6 eyes (30\%) before surgery, in 13 eyes (65\%) at day 1, in 12 eyes (60\%) at week 1 and in 2 (10\%) eyes on the at week 4, only one eye (5\%) had more than $1+$ anterior chamber cell activity 12 weeks after surgery (Table 2). Anterior chamber flare assessments are presented in table 2.

All patients had vitreous haze of $2+$ or greater before surgery, after surgery all patients has less than $2+$ vitreous haze (Table 2 ).

Mean IOP before the procedure was $13.9 \pm 2.8 \mathrm{mmHg}$ and mean IOP on day 1 , week 1 , week 4 and week 12 were $11.7 \pm 4.3 \mathrm{mmHg}$, $14.5 \pm 8.4 \mathrm{mmHg}, 14.2 \pm 5.7 \mathrm{mmHg}$ and $14.5 \pm 5.1 \mathrm{mmHg}$, respectively (Table 2 ).

Table 1. Etiology of uveitis

\begin{tabular}{lc}
\hline Etiology & $\begin{array}{c}\text { Number of eyes } \\
\mathbf{n}(\%)\end{array}$ \\
\hline Toxoplasmic retinochoroiditis & $11(55.0)$ \\
Tuberculous uveitis & $2(10.0)$ \\
Behçet's disease & $1(5.0)$ \\
Vogt-Koyanagi-Harada disease & $1(5.0)$ \\
Sarcoidosis & $1(5.0)$ \\
Sympathetic ophthalmia & $1(5.0)$ \\
Pars planitis & $1(5.0)$ \\
ldiopathic diffuse uveitis & $2(10.0)$ \\
\hline
\end{tabular}

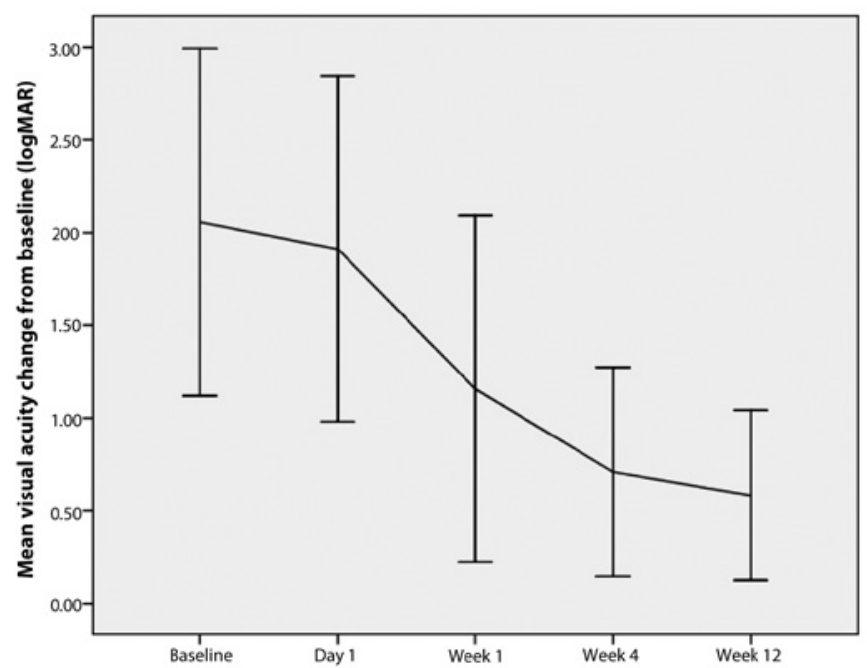

Figure 1. Mean change from baseline over time in visual acuity. Vertical bars are \pm 1 standard deviations from the mean. 
Table 2. Visual acuity (logMAR), intraocular pressure (IOP-mmHg), anterior chamber (AC) cell reaction, anterior chamber (AC) flare and vitreous haze during the follow-up

\begin{tabular}{|c|c|c|c|c|c|c|}
\hline & Baseline & Day 1 & Week 1 & Week 4 & Week 12 & $\mathbf{p}^{+}$ \\
\hline Visual acuity (mean \pm SD) & $2.06 \pm 0.94$ & $1.91 \pm 0.93$ & $1.16 \pm 0.94^{*}$ & $0.71 \pm 0.56^{*}$ & $0.58 \pm 0.46^{*}$ & $<0.001$ \\
\hline $\mathrm{IOP}($ mean $\pm \mathrm{SD})$ & $13.9 \pm 2.8$ & $11.7 \pm 4.3$ & $14.5 \pm 8.4$ & $14.2 \pm 5.7$ & $14.5 \pm 5.1$ & 0.164 \\
\hline AC cells $\geq 1+[n(\%)]$ & $6(30 \%)$ & $13(65 \%)$ & $12(60 \%)$ & $2(10 \%)$ & $1(5 \%)$ & \\
\hline AC flare $\geq 1+[n(\%)]$ & $5(25 \%)$ & $13(65 \%)$ & $9(45 \%)$ & $2(10 \%)$ & $1(5 \%)$ & \\
\hline Vitreous haze $\geq 1+[\mathrm{n}(\%)]$ & $20(100 \%)$ & $6(30 \%)$ & $4(20 \%)$ & $2(10 \%)$ & $1(5 \%)$ & \\
\hline
\end{tabular}

${ }^{+}=$Friedman's repeated-measures analysis of variance on ranks

${ }^{*}=P<0.05$ by post hoc Tukey test compared to preoperative (pre-op)

No case of infective endophthalmitis occurred. Postoperative hypotony was seen in three eyes and was associated with peripheral choroidal detachment in two eyes. Secondary cataract progression occurred in three eyes in our series (20.0\% of the phakic eyes) during the follow-up period and phacoemulsification with intraocular lens implantation was performed in two of them before the final visit. One eye that underwent subtenon injection of triamcinolone acetonide experienced an IOP elevation with poor response to appropriate clinical therapy and was further referred to glaucoma filtering surgery. One patient with toxoplasmic retinochoroiditis had a relapse during the second month of follow-up and was successfully treated with trimethoprim/sulfamethoxazole associated with systemic prednisone. His visual acuity at the last visit (week 12) was 0.50 logMAR.

\section{DISCUSSION}

Intraocular surgery has been reported to induce exacerbations in different types of uveitis ${ }^{(1-4,14-20)}$. In cataract surgery, the surgical management with small incisions allowed minimization of surgical trauma and inflammatory response lowering the rate of complications with better visual prognosis for the patients ${ }^{(3,4)}$. In posterior segment surgery, the new transconjunctival sutureless vitrectomy systems have the same premises, minimizing surgical manipulation and hastening of postoperative recovery, resulting in a decreased postoperative intraocular inflammatory response ${ }^{(5,6)}$.

The use of more flexible and smaller-gauge vitrectomy probes have some limitations, like lesser ability to move the eye, reduced cutting and aspirating speed ${ }^{(15,20)}$. A careful selection of patients is crucial and vitreoretinal conditions requiring minimal intraocular manipulation and tissue dissection are usually better indicated for this type of procedure ${ }^{(15)}$. None of our patients required suture placement or conversion to 20-gauge technique; this fact is related to the meticulous indication of surgeries. As many of these patients had media haziness with impaired visualization of the fundus, ocular ultrasonography was a valuable tool in the preoperative evaluation of these patients.

None of our patients developed fibrin formation or new posterior synechia; this fact can be related to the adequate preoperative and postoperative control of inflammation. Postoperative hypotony and cataract progression were the most frequent complications seen and both occurred in three eyes. Postoperative hypotony is a known complication of sutureless surgical procedures and is most likely to occur in the first postoperative day $y^{(5-10)}$. In two of our patients it was associated with peripheral choroidal detachment, but they resolved spontaneously during the first week and did not require further surgical procedure. Cataract formation is also a common complication following pars plana vitrectomy and uveitis and occurred in $20.0 \%$ of our phakic patients in a three month follow-up period. Two patients with significant lens opacities successfully undergone phacoemulsification with IOL implantation. Worsening of cataract is expected in more patients of our series in a longer follow-up as shown on a previous study ${ }^{(10)}$. One eye presented on week 1 an IOP of $30 \mathrm{mmHg}$ and maintained ocular hypertension despite adequate clinical management, being further referred to glaucoma filtering surgery; this eye underwent an intraoperative subtenon triamcinolone acetonide injection and this procedure could be the cause of these finding. Uveitis relapse was seen in only one eye in our series, this patient had toxoplasmic retinochoroiditis and developed a re-activation in the second month of follow-up; an increased risk of reactivation of ocular toxoplasmosis following cataract surgery was described by Bosch-Driessen et al., ${ }^{(17)}$ reactivation occurred in 5/15 eyes within four months of cataract surgery (three within three months), a higher rate than we have found.

Sutureless ophthalmic surgery has been associated with an increased risk of endophthalmitis(18-20), this is also a concern in $25 \mathrm{~g}$ PPV and a prospective study will be needed to settle this issue. Our patients were carefully prepared with povidone-iodine, the lashes were draped during surgery, prophylactic antibiotic was used in the postoperative period and no cases of endophthalmitis were seen.

In patients with residual vitritis due to posterior segment inflamation, $25 \mathrm{~g}$ PPV showed to be a feasible and safe technique, with low postoperative inflammatory response and relapse rate. Vitreous clearance and visual acuity improvement was achieved in all patients without any major intraoperative or postoperative complication. As a diagnostic procedure $25 \mathrm{~g}$ PPV can play an important role once it produced only minimal surgical trauma and inflammatory response. Besides that, the technique shows advantages as the preservation of an intact conjunctiva in patients who are at risk of needing glaucoma filtration surgery or who already have filtering blebs ${ }^{(21)}$. An improvement in the course of uveitis after pars plana vitrectomy was described previously ${ }^{(1-3)}$, in our study the follow-up period was too short to perform such type of evaluation, although, anterior chamber cells activity and flare decreased from the preoperative to the final visit and this could be an indicator of better control of inflammation.

\section{CONCLUSION}

Twenty-five gauge vitrectomy has proven its efficacy on cleansing vitreous opacities and improving visual acuity on patients with residual vitritis secondary to uveitis with minimal postoperative inflammation and complications related to the procedure.

\section{REFERENCES}

1. Bovey EH, Herbort CP. Vitrectomy in the management of uveitis. Ocul Immunol Inflamm. 2000;8(4):285-91.

2. Becker M, Davis J. Vitrectomy in the treatment of uveitis. Am J Ophthalmol. 2005; 140(6):1096-105.

3. Nussenblatt RB. Role of surgery in the patient with uveitis. In: Nussenblatt RB, Whitcup SM, editors. Uveitis: fundamentals and clinical practice. $3^{\text {rd }}$ ed. St. Louis: Mosby; 2003. p.137-56.

4. Androudi S, Ahmed M, Fiore T, Brazitikos P, Foster CS. Combined pars plana vitrectomy and phacoemulsification to restore visual acuity in patients with chronic uveitis. J Cataract Refract Surg. 2005;31(3):472-8.

5. Fujii GY, De Juan E Jr, Humayun MS, Chang TS, Pieramici DJ, Barnes A, Kent D. Initial 
experience using the transconjunctival sutureless vitrectomy system for vitreoretinal surgery. Ophthalmology. 2002;109(10):1814-20.

6. Fujii GY, De Juan EJr, Humayun MS, Pieramici DJ, Chang TS, Awh C, et al. A new 25-gauge instrument system for transconjunctival sutureless vitrectomy surgery. Ophthalmology. 2002;109(10):1807-12; discussion 1813. Erratum in: Ophthalmology. 2003; 110(1):9.

7. Kellner L, Wimpissinger B, Stolba U, Brannath W, Binder S. 25-gauge vs 20-gauge system for pars plana vitrectomy: a prospective randomised clinical trial. Br J Ophthalmol. 2007;91(7):945-8.

8. Rizzo S, Genovesi-Ebert F, Murri S, Belting C, Vento A, Cresti F, Manca ML. 25-gauge, sutureless vitrectomy and standard 20-gauge pars plana vitrectomy in idiopathic epiretinal membrane surgery: a comparative pilot study. Graefes Arch Clin Exp Ophthalmol. 2006:244(4):472-9.

9. Kadonosono K, Yamakawa T, Uchio E, Yanagi Y, Tamaki Y, Araie M. Comparison of visual function after epiretinal membrane removal by 20-gauge and 25-gauge vitrectomy. Am J Ophthalmol. 2006;142(3):513-5.

10. Ibarra MS, Hermel M, Prenner JL, Hassan TS. Longer-term outcomes of transconjunctival sutureless 25-gauge vitrectomy. Am J Ophthalmol. 2005;139(5):831-6.

11. Jabs DA, Nussenblatt RB, Rosenbaum JT; Standardization of Uveitis Nomenclature (SUN) Working Group. Standardization of uveitis nomenclature for reporting clinical data. Results of the First International Workshop. Am J Ophthalmol. 2005;140(3):509-16.

12. Nussenblatt RB, Palestine AG, Chan CC, Roberge F. Standardization of vitreal inflammatory activity in intermediate and posterior uveitis. Ophthalmology. 1985:92(4):467-71.
13. Holladay JT. Proper method for calculating average visual acuity. J Refract Surg. 1997; 13(4):388-91.

14. Sonoda KH, Enaida H, Ueno A, Nakamura T, Kawano Yl, Kubota T, et al. Pars plana vitrectomy assisted by triamcinolone acetonide for refractory uveitis: a case series study. Br J Ophthalmol. 2003:87(8):1010-4

15. Lakhanpal RR, Humayun MS, de Juan E Jr, Lim JI, Chong LP, Chang TS, et al. Outcomes of 140 consecutive cases of 25-gauge transconjunctival surgery for posterior segment disease. Ophthalmology. 2005;112(5):817-24.

16. Miyahara T, Ohta K, Yamamoto Y, Ueno A, Murata T. 25-gauge vitrectomy to treat ocular complications of familial amyloid polyneuropathy. J Glaucoma. 2007:16(1):169-70.

17. Bosch-Driessen LH, Plaisier MB, Stilma JS, Van der Lelij A, Rothova A. Reactivations of ocular toxoplasmosis after cataract extraction. Ophthalmology. 2002;109(1):41-5.

18. Martidis A, Chang TS. Sutureless 25-gauge vitrectomy: risky or rewarding? Ophthalmology. 2007;114(12):2131-2

19. Kunimoto DY, Kaiser RS; Wills Eye Retina Service. Incidence of endophthalmitis after 20- and 25-gauge vitrectomy. Ophthalmology. 2007;114(12):2133-7. Comment in Ophthalmology. 2007;114(12):2131-2

20. Chen JK Khurana RN, Nguyen QD, Do DV The incidence of endophthalmitis following transconjunctival sutureless 25- vs 20-gauge vitrectomy. Eye (Lond). 2009;23(4): 780-4 21. Soheilian M, Mirdehghan SA, Peyman GA. Sutureless combined 25-gauge vitrec tomy, phacoemulsification, and posterior chamber intraocular lens implantation for management of uveitic cataract associated with posterior segment disease. Retina. 2008;28(7):941-6.

\title{
VI Congreso ALACCSA-R Asociación Latinoamericana de Cirujanos de Catarata, Segmento Anterior y Refractiva
}

\author{
04 a 06 de outubro de 2012 \\ Hotel Hilton Puerto Madero \\ Buenos Aires - Argentina
}

